\title{
Potassium Chromate
}

National Cancer Institute

\section{Source}

National Cancer Institute. Potassium Chromate. NCI Thesaurus. Code C45889.

A yellowish, crystalline, inorganic compound that emits toxic chromium fumes upon heating. Potassium chromate is highly corrosive and is a strong oxidizing agent. This substance is used in the manufacture of dyes and in textile dyeing processes. Potassium chromate primarily affects the nose, throat and lungs causing ulcerations, shortness of breath, bronchitis, pneumonia and asthma but can also affect the gastrointestinal tract, liver, kidneys and immune system. This substance is a known human carcinogen and is associated with an increased risk of developing lung cancer and cancer of the sinonasal cavity. ( $\mathrm{NCl05)}$ 